\title{
Alder og alvor
}

\author{
Det er brei semje om at alvorleg sjukdom skal ha høgare prioritet i den norske helsetenesta enn mindre \\ alvorleg sjukdom. Samtidig er det svært kontroversielt å legge vekt på alder ved prioritering. I praksis kan \\ ein, slik eg ser det, ikkje legge vekt på «alvor» utan samtidig å «aldersdiskriminere», og vi må velje mellom \\ å gi relativ prioritet til unge eller relativ prioritet til eldre.
}

Bjarne Robberstad

bjarne.robberstad@uib.no

Norheimutvalet har foreslått å erstatte dagens «alvorlighetskriterium» med eit nytt «helsetapskriterium» (1). Forslaget har skapt debatt og er blitt kritisert for å vere eit alderskriterium som diskriminerer eldre. Helseminister Bent Høie seier i Aftenposten 16. juni 2015 at helsetapskriteriet er for «teoretisk og vanskelig», og saka er spissa med tittelen Alder blir ikke avgjørende for behandling (2). Eg meiner debatten viser at det er behov for å rydde i terminologien om kva som gjer ein tilstand «alvorleg». Det er naudsynt med ein gjennomgang av korleis dei alternative definisjonane vert påverka av alder.

\section{Kva gjer ein sjukdom alvorleg?}

Alvor blei foreslått som prioriteringskriterium av Lønning II-utvalet, saman med nytte og kostnadseffektivitet. Utvalet meinte at alvoret ved ein tilstand skulle vere basert på prognosetapet i mangel av behandling eller andre tiltak og vurderast $i$ forhold til a) risiko for død eller funksjonstap, b) graden av fysisk og psykisk funksjonstap og c) smerter, fysisk eller psykisk ubehag (3). Trass i at prinsippet raskt blei implementert gjennom lov og forskrift, t.d. prioriteringsforskrifta, har definisjonen vist seg vanskeleg å nytte på ein konsistent måte ved prioriteringar i praksis. For det første er den utydeleg på korleis framtidig og tidlegare helse skal vurderast. Medan punkt (a) openbart gjeld framtidig helse, kan (b) og (c) forståast både framover og bakover i tid. For det andre har graden av prognosetap aldri blitt presisert, t.d. kor stor risikoen for funksjonstap skal vere før ein tilstand er alvorleg.

Alvor kan operasjonaliserast på sju ulike måtar ved hjelp av ein enkel figur, med levetid horisontalt og helserelatert livskvalitet vertikalt (fig 1). Jan Abel Olsen, professor i helseøkonomi, nytta eit liknande rammeverk, men avgrensa diskusjonen til fire ulike definisjonar (4). I figuren representerer y-aksen helserelatert livskvalitet og $\mathrm{x}$-aksen leveår. Den raude kurva er eit tenkt eksempel som illustrerer helseprofilen til ein person som vert sjuk om lag midt i livet. Området under kurva (integralet) kan kallast «gode leveår». Kor alvorleg er så denne sjukdomen? Svaret kjem an på om ein vurderer graden av dårleg helse på diagnosetidspunktet, dårleg helse i framtida (prognose) eller over livsløpet $(5,6)$.

\section{Helsenivå på diagnosetidspunktet}

(i) Alvor $=1-\mathrm{Hd}$ (Reduksjon i helsenivå ved diagnose)

Denne definisjonen tek utgangspunkt i pasienten sitt akutte behov for hjelp med å vektlegge grad av dårleg helsetilstand her og nå $(1-\mathrm{Hd})$. Den kan begrunnast ut frå omsynet til behov for akutt hjelp, eller «ruleof-rescue»-prinsippet. Definisjonen er retta berre mot helserelatert livskvalitet og er kanskje den vanlegaste måten å omtale «alvor» (severity) på i litteraturen $(4,7-9)$. Ved å vurdere «alvor» på diagnosetidspunktet som 1-Hd ser ein vekk frå tidsdimensjonen. Prinsippet er såleis den einaste måten å vurdere alvor på som er heilt uavhengig av alder. Dette er samtidig den største svakheita ved metoden, då varighet åpenbart er relevant for kor alvorleg ein sjukdom er. Det er neppe «alvorleg» å gjennomføre smertefull boring i ei tann utan bedøving, fordi det er så kortvarig. Men tilsvarande smerte som ein kronisk tilstand er bokstaveleg talt ikkje til å leve med.

\section{Framtidig helse (prognose)}

(ii) Alvor $=\mathrm{Tu}-\mathrm{Td}$ (Forventa levetid ved diagnose)

Den andre definisjonen vurderer grad av alvor basert på forventa gjenverande levetid utan behandling $(\mathrm{Tu}-\mathrm{Td})$, og kan også begrunnast ut frå pasienten sitt akutte behov for hjelp (rule-of-rescue). Med denne definisjonen vert kort gjenverande levetid vurdert som meir alvorleg enn når prognosen er lenger. Slike «mot slutten av livet»-vurderingar vert lagt vekt på av engelske helsemyndigheiter (10). Begge dei to første definisjonane har berre éin dimensjon av helse og er såleis overforenklande. For eksempel ignorerer 1 - Hd prognose i høve til over- leving, medan $\mathrm{Tu}-\mathrm{Td}$ ignorerer akutt behov for smertelindring.

(iii) Alvor $=$ A3 (Forventa gode leveår ved diagnose)

Ein tredje mulighet er å vurdere prognose som kombinasjonen av helserelatert livskvalitet og gjenverande levetid utan behandling (området A3). Dette er kanskje det alternativet som ligg tettast opp mot Lønning II-utvalet sin definisjon av alvor (3) og er det som er anbefalt i Helsedirektoratet sin rettleiar for økonomisk evaluering (11). I litteraturen vert «severity» nytta både om definisjon (i), (ii) og (iii) (8). I utgangspunktet kan ein hevde at Tu-Td er uavhengig av alder (4). Men ofte er prognosen påverka av pasienten sin alder, til dømes dei fleste kreftformene (12). I praksis vil difor både alternativ (ii) og (iii) indirekte vere påverka av pasienten sin alder. Ved høg alder, når forventa levetid for ein frisk person $\left(\mathrm{T}^{*}\right)$ er kortare enn forventa prognose for ein gjennomsnittspasient $\left(\mathrm{T}^{*}-\mathrm{Td}\right)<(\mathrm{Tu}-\mathrm{Td})$, er samvariasjonen mellom alder og alvor svært høg.

To alternative definisjonar vurderer kor alvorleg sjukdommen er basert på framtidig helse på ein meir sofistikert måte:

(iv) Alvor $=\left(\mathrm{T}^{*}-\mathrm{Tu}\right) /\left(\mathrm{T}^{*}-\mathrm{Td}\right) \times 100 \%$ (Relativt framtidig tap av leveår)

(v) Alvor $=$ B2 $/(\mathrm{A} 3+\mathrm{B} 2) \times 100 \%$ (Relativt framtidig tap av gode leveår)

Utgangspunktet for desse to definisjonane er realisering av pasienten sitt helsepotensial. Dette blir rekna ut som brøken av helsetapet med sjukdom over gjenverande helse i mangel av sjukdom på diagnosetidspunktet, anten basert på levetid (iv) eller gode leveår (v). Alvor er med denne definisjonen eit uttrykk for kor mykje av den forventa framtidige helsa pasienten mister som følge av sjukdomen, altså det relative framtidige helsetapet (13). Relativt helsetap er blitt foreslått som prioriteringskriterium av nederlandske forskarar (14).

Tidlegare helse vert med denne definisjonen sett på som irrelevant, og relativt helsetap ignorerer såleis historikken til for 
eksempel kronikarar. Relativt helsetap er matematisk sett ein ratio og blir kritisert for å tilsløre storleiken av helsetapet (15). Eit helsetap på fem dagar når forventa levetid er ti dagar blir vurdert som like alvorleg som eit helsetap på fem år når forventa levetid er ti år. I den norske debatten har det vore argumentert for at relativt helsetap er eit aldersnøytralt begrep for alvor (16). Dette er ikkje korrekt. Tvert om er det slik at «alvoret» ved eit gitt helsetap med dette prinsippet aukar med alderen, noko som skjer fordi arealet B2 minker med alder og fordi B2 står under brøkstreken i (v). Det er eit trivielt matematisk poeng, men med etiske implikasjonar som ikkje alle vil vere komfortable med. Med ein referansealder på 80 , slik Norheimutvalet føreslår, betyr det t.d. at tap av eitt godt leveår for ein 78åring (t.d. prostatakreft) vert vurdert som 40 gongar meir «alvorleg» enn tap av eitt godt leveår for ein 1-åring (t.d. barnekreft) (tab 1). I den grad det kan seiast at helsetapskriteriet er «aldersdiskriminerande», kan ein altså seie at relativt framtidig helsetap er «omvendt aldersdiskriminering».

I staden for fast referansealder kan ein nytte forventa gjenverande levetid ved ulik alder, altså basert på leveårstabellar (17). Dette reduserer utslaga for relativ prioritet ved høg alder, men endrar ikkje faktumet at metoden er «omvendt aldersdiskriminerande» og at relativ prioritet aukar eksponentielt med alder (tab 2).

\section{Helsetap over livsløpet}

(vi) Alvor $=\mathrm{T}^{*}-\mathrm{Tu}$ (absolutt tap av leveår) (vii) Alvor $=$ B1 + B2 (absolutt tap av gode leveår)

Desse to definisjonane fokuserer på pasienten sitt absolutte helsetap, anten i form av tapte leveår $\left(\mathrm{T}^{*}-\mathrm{Tu}\right)$ eller i form av gode leveår over livsløpet (B1 + B2). Det andre av desse samsvarer med helsetapskriteriet, slik det er føreslått av Norheimutvalet (1), og er basert på Williams sitt «fair innings»argument (18). Etter denne definisjonen måler vi «alvor» som helsetapet heile livet sett under eitt, inkludert tida både før og etter diagnosetidspunktet. Dersom alt anna er likt, så vil langvarig sjukdom med denne definisjonen bli vurdert som meir alvorleg enn kortvarig sjukdom. Det er altså helsetapet over livsløpet som er relevant for alvor (B1 + B2), og ikkje alderen (Td) (19).

Dette prinsippet er blitt kritisert for i praksis å vere eit alderskriterium, der prioriteten går ned med aukande alder (17). Dette er korrekt i den forstand at sjukdom som er kronisk og som rammar i ung alder per definisjon varer lenger, gir større helsetap og høgare prioritet enn tilsvarande sjukdom seinare i livet. Men effekten er indi-

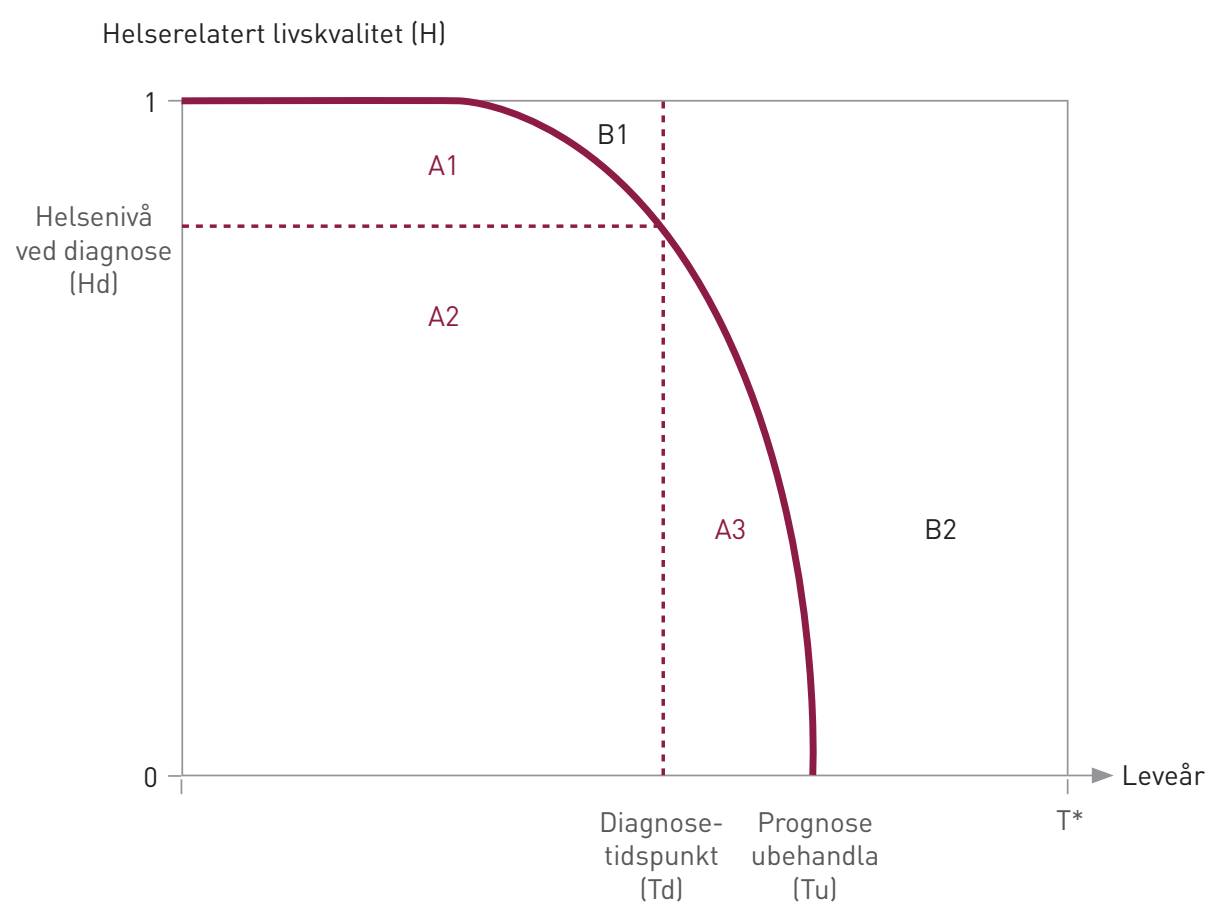

Figur 1 Verdien 1 representerer best tenkelege helse, verdien 0 verst tenkelege helse (død), medan $T^{*}$ er forventa levealder utan sjukdom. Den raude kurva illustrerer helseprofilen til ein person som vert sjuk om lag midt i livet. Diagnosen vert stilt på tidspunkt Td når helsenivået er Hd. Utan behandling vil helsa gradvis bli svekka og pasienten kan forvente å leve til tidspunktet Tu

rekte, og det er slik at sjukdom som set ned livskvaliteten mykje til eldre vil kunne bli vurdert som meir alvorleg enn sjukdom som set ned livskvaliteten i mindre grad til yngre pasientar. Det er også slik at langvarig sjukdom for eldre gir større helsetap enn kortvarig sjukdom for yngre pasientar. Argumentet om ein direkte samanheng mellom alvor og alder (16) er såleis ikkje korrekt.

Absolutt helsetap som mål på alvor er ikkje utan utfordringar. Metoden tek indirekte omsyn til prognosen utan behandling vurdert som produktet av levetid ubehandla og grad av dårlig helsetilstand (område A3 i figuren, som endrar seg like mykje, men med motsett forteikn som B2 med behandling). Men prinsippet kan vere insensitivt for svært akutte problemstillingar $(1-\mathrm{Hd})$ der varigheten $(\mathrm{Tu}-\mathrm{Td})$ er såpass kortvarig at A3 vert lite (t.d. anestesi ved kirurgi). Det bør difor undersøkast kva prioriteringsmessige konsekvensar dette kan gi i praksis.

\section{Age before beauty?}

Norheimutvalet si innstilling har vore på høyring, og Stortinget skal ta stilling til korleis alvor skal operasjonaliserast og vektast ved helseprioriteringar. Olsen har foreslått ei firedeling av begrepet alvor (4), inkludert alternativa (i), (ii), (iii) og (vii), medan eg her også inkluderer relativt framtidig helse- tap i form av leveår (iv), gode leveår (v) og absolutt tap av leveår over livsløpet (vi). I dei sju alternativa er det lagt vekt på ulike ting, og dei er på ulike vis sensitive for pasienten sin alder.

Alternativ (i) og (ii) er overforenklande og overser begge faktorane som er klart vesentlege for kva som gjer ein tilstand alvorleg. Det same kan ein etter mitt syn seie om alternativ (iv) og (vi), sidan begge ser vekk frå helserelatert livskvalitet. Ein står såleis att med tre alternativ som kan vurderast nærare, nemleg alternativ (iii), (v) og (vii).

Alvor definert som forventa gode leveår ved diagnose (iii) ligg kanskje tettast opp mot dagens definisjon utarbeida av Lønning II-utvalet og slik det står i prioriteringsforskrifta. Det er sjølvsagt mogleg å presisere tydelegare korleis definisjonen skal nyttast i praksis (9). Men prinsippet vil uansett legge stor vekt på risiko for snarleg død, altså «end-of-life», og i praksis er det difor størst vekt på sjukdom som rammar eldre i forhold til sjukdom som rammar yngre pasientar.

Relativt framtidig helsetap, alternativ (v), vil også gi sterk prioritet til eldre framfor yngre. Det er i tillegg lett å vise at denne vektinga i favør av eldre er eksponentiell. Sidan både alternativ (iii) og (v) favoriserer eldre, vil begge trekke i retning av å semen- 
Tabell 1 Samanhengen mellom alder og alvor når det framtidige helsetapet er eitt godt leveår for alle og når relativt framtidig helsetap vert nytta som definisjon. Dømet viser at relativt framtidig helsetap er «omvendt aldersdiskriminerande» og at relativ prioritet til eldre aukar eksponentielt

\begin{tabular}{lcccc}
$\begin{array}{c}\text { Pasient } \\
\text { lalder) }\end{array}$ & $\begin{array}{c}\text { Framtidig gode } \\
\text { leveår utan } \\
\text { sjukdom (A3+B2) }\end{array}$ & $\begin{array}{c}\text { Framtidig } \\
\text { helsetap (B2) }\end{array}$ & $\begin{array}{c}\text { Alvorlighet }= \\
\text { B2/(A3+B2) } \\
(\%)\end{array}$ & $\begin{array}{c}\text { Relativ } \\
\text { prioritet }\end{array}$ \\
$1 \mathrm{a} r$ & 79 & 1 & 1,3 & 1,0 \\
$10 \mathrm{a} r$ & 70 & 1 & 1,4 & 1,1 \\
$40 \mathrm{ar}$ & 40 & 1 & 2,5 & 2,0 \\
$70 \mathrm{a} r$ & 10 & 1 & 10 & 7,9 \\
$78 \mathrm{a} r$ & 2 & 1 & 50 & 40 \\
\hline
\end{tabular}

Tabell 2 Samanhengen mellom alder og alvor når framtidige gode leveår er basert på leveårstabell (17) i staden for ein fast referansealder

\begin{tabular}{lcccc}
\hline $\begin{array}{l}\text { Pasient } \\
\text { lalder) }\end{array}$ & $\begin{array}{c}\text { Framtidig gode } \\
\text { leveår utan } \\
\text { sjukdom (A3+B2) }\end{array}$ & $\begin{array}{c}\text { Framtidig } \\
\text { helsetap (B2) }\end{array}$ & $\begin{array}{c}\text { Alvorlighet }= \\
\text { B2/(A3+B2) } \\
(\%)\end{array}$ & $\begin{array}{c}\text { Relativ } \\
\text { prioritet }\end{array}$ \\
$1 \mathrm{ar}$ & 80,9 & 1 & 1,2 & 1,0 \\
$10 \mathrm{ar}$ & 71,9 & 1 & 1,4 & 1,1 \\
$40 \mathrm{ar}$ & 42,6 & 1 & 2,4 & 1,9 \\
$70 \mathrm{ar}$ & 16,0 & 1 & 6,0 & 4,9 \\
$78 \mathrm{a} r$ & 10,3 & 1 & 10 & 7,7 \\
\hline
\end{tabular}

tere eksisterande skilnader i livsløpshelse mellom pasientgrupper. Dette skjer fordi prioritet til dei sterkaste (i betydningen oppnådd livsløpshelse) impliserer nedprioritering av dei svakaste pasientgruppene.

Helsetapskriteriet, eller absolutt tap av gode leveår, alternativ (vii), gir relativt høgare prioritet til pasientgrupper med store helsetap og langvarig sjukdom. Dette appellerer difor til dei som er opptekne av at helsetenesta skal bidra til å jamne ut helseskilnader i samfunnet i eit livsløpsperspektiv. Prinsippet har også empirisk støtte, både frå England (20), Nederland (21) og Noreg (10). Men prinsippet ståande aleine kan vere insensitivt for enkelte akuttmedisinske problemstillingar. Norheimutvalet meiner at dette omsynet vert fanga opp av det foreslåtte «helsegevinstkriteriet» (1), men gjennom anvendt forsking bør det greiast betre ut om summen av eit slikt pluralistisk perspektiv er i samsvar med folk sine preferansar og verdigrunnlaget for helsetenesta.

Spørsmålet om alder og alvor er sensitivt og engasjerer, men debatten om aldersdiskriminering har så langt vore unøyaktig, unyansert og i sum meir forvirrande enn nyttig, noko oppslaget i Aftenposten 16.6. 2015 illustrerer på ein god måte (2). Sidan det er normativt svært problematisk å sjå vekk frå varigheten av ein sjukdom når vi vurderer alvor, har vi ingen gode aldersnøytrale alternativ for å operasjonalisere begrepet. Valet står etter mitt skjønn i røynda mellom to alternativ som indirekte favoriserer eldre, og eitt alternativ som indirekte favoriserer yngre pasientar. Det engelske uttrykket «age before beauty» blir nytta for å gi forrang til eldre personar, t.d. når det ikkje er tilstrekkeleg med sitteplassar på bussen. Er det slik vi ønskjer det også for den norske helsetenesta? Eg tillèt meg å vere usamd.

\section{Bjarne Robberstad (f. 1965)}

er professor i helseøkonomi ved Universitetet i Bergen, tidlegare leiar av Blåreseptnemnda og avtroppande medlem i Nasjonalt råd for kvalitet og prioritering i helsetenesta.

Forfattaren har fylt ut ICMJE-skjemaet og oppgir følgjende interessekonfliktar: Han er kollega med Ole Frithjof Norheim og har vore forfattar saman med han ved fleire høve.
Litteratur

1. NOU 2014: 12. Åpent og rettferdig - prioriteringer i helsetjenesten. www.regjeringen.no/no/ dokumenter/NOU-2014-12/id2076730/ (17.5.2015)

2. Dommerud T. Alder blir ikke avgjørende for behandling. Aftenposten 16.6. 2015 www.aftenposten.no/nyheter/iriks/Alder-blirikke-avgjorende-for-behandling-8060667.html (17.6. 2015)

3. NOU 1997: 18. Prioritering på ny. Gjennomgang av retningslinjer for prioriteringer innen norsk helsetjeneste. www.regjeringen.no/no/dokumenter/ nou-1997-18/id140956/ (17.5.2015).

4. Olsen JA. Hva menes med «sykdommens alvorlighetsgrad»? Tidsskr Nor Legeforen 2013; 133: 64-7.

5. Nord E. Concerns for the worse off: fair innings versus severity. Soc Sci Med 2005; 60: 257-63.

6. Brock D. Priority to the worst off in health care resource prioritisation. I: Battin M, Rhodes $\mathrm{R}$, Silvers A, red. Health care and social justice. New York, NY: Oxford University Press, 2001.

7. Nord E, Johansen R. Concerns for severity in prio rity setting in health care: a review of trade-off data in preference studies and implications for societal willingness to pay for a QALY. Health Policy 2014; 116: $281-8$

8. Shah KK. Severity of illness and priority setting in healthcare: a review of the literature. Health Policy 2009; 93: 77-84

9. Bordvik M. Slik kan de nye kriteriene slå ut. Dagens Medisin 2015; sect. 4-5.

10. Olsen JA. Priority preferences: «end of life» does not matter, but total life does. Value Health 2013 16: $1063-6$

11. Økonomisk evaluering av helsetiltak - en veileder Oslo: Helsedirektoratet, 2012.

12. Småstuen M, Aagnes $B$, Johannesen T et al. Longterm cancer survival: Patterns and trends in Norway 1965-2007. Oslo: Kreftregisteret, 2008.

13. Johannesson M. Should we aggregate relative or absolute changes in QALYs? Health Econ 2001; 10 573-7.

14. Stolk EA, van Donselaar G, Brouwer WB et al. Reconciliation of economic concerns and health policy: illustration of an equity adjustment procedure using proportional shortfall. Pharmacoeconomics 2004; 22: 1097-107.

15. Lindemark F, Norheim OF, Johansson KA. Making use of equity sensitive QALYs: a case study on identifying the worse off across diseases. Cost Eff Resour Alloc 2014; 12: 16.

16. Nord E. Helsevesen er ikke jordbruk. Overlegen 2014; nr. 4: 5

17. Statistisk sentralbyrå. Statistikkbanken. www.ssb.no/statistikkbanken/ (8.6.2015)

18. Williams A. Intergenerational equity: an exploration of the 'fair innings' argument. Health Econ 1997: 6: 117-32

19. Ottersen T. Lifetime QALY prioritarianism in priority setting. J Med Ethics 2013; 39: 175-80.

20. Dolan P. Tsuchiya A. Health priorities and public preferences: the relative importance of past health experience and future health prospects. J Health Econ 2005; 24: 703-14.

21. Stolk EA, Pickee SJ, Ament AH et al. Equity in health care prioritisation: an empirical inquiry into social value. Health Policy 2005; 74: 343-55.

Motteke 27.3. 2015, første revisjon sendt inn 1.6. 2015, godkjent 17.6. 2015. Redaktør: Siri Lunde Strømme.

Publisert først på nett.

Engelsk omsetjing på www.tidsskriftet.no 